\title{
Metaphorical Folk Names of English and Ukrainian Homeopathic Plants: Comparative Analysis in Cognitive and Linguocultural Framework
}

\author{
Nataliia Kravchenko \\ Kyiv National Linguistic University, Kyiv, Ukraine \\ Nataliia Yemets \\ Kyiv National Linguistic University, Kyiv, Ukraine \\ Olha Kurbal-Hranovska \\ Kyiv National Linguistic University, Kyiv, Ukraine
}

\begin{abstract}
This research focuses on the comparative analysis of metaphorical folk names of English and Ukrainian homeopathic plants. The paper identified and interpreted the cognitive and linguocultural underpinning of the metaphors with an emphasis on the isomorphic and allomorphic features of their motivational structures in the compared languages. The study reached four major findings. Isomorphic for the metaphorization processes are input source spaces of "plant distribution area"; "mythical person or creature"; "a diseased organ or symptom"; "behaviour"; "another plant"; "body parts of the animal, bird or human", associated with the plant as a target space in shape, general appearance, location, healing properties, time of existence and way of life. Isomorphic for English and Ukrainian folk names of homeopathic plants are the compound blending models involving more than two input spaces and few blending spaces, as well as the presence in their motivational structure of a symbolic component associated with nationally specific and universal archetypal symbols. Isomorphic for metaphoric plant names is metonymic compression in blending spaces, based on holonym-partonym substitution, and involvement in the blending the possessive and comparative schemas. Allomorphic input sources of English metaphors involve the spheres of "artifact", "body fluids", "mythological characters", "fantastic creature", "particular patterns of behavior"- in contrast to the Ukrainian intercultural synonyms where such conceptual input spaces have not been identified.
\end{abstract}

Index Terms - folk names, conceptual integration, linguocultural

\section{INTRODUCTION}

Folk names of diseases, plants, and medicines related to the peculiarities of worldview in different linguistic cultures constitute a considerable part of therapeutic terminological systems of various languages, including Ukrainian and English, functioning along with synonymous duplicates of Greek and Latin origin.

Cognitive-conceptual reconstruction of the internal form of such words is a means of understanding the worldviews of different cultures, the specifics of their conceptualization and categorization of nature and the surrounding realities.

The purpose of the article is to offer the cognitive-conceptual model of comparative analysis of English and Ukrainian homeopathic metaphorically-based nominations from viewpoint of isomorphic and allomorphic nominative models, their corresponding domains and prominent features implicated by the internal form of the terms.

\section{THEORETICAL FRAMEWORK}

In exploring cognitive metaphors this paper bases on the theory of conceptual integration (Fauconnier, Turner, 1996, 1998, 2000, 2002). The key premise of the theory is the concept of mental space as the area of conceptualization, structured through frames and various cognitive models: image-schematic, propositional, metaphorical, metonymic, symbolic, etc. The theory postulates the existence of a basic four-space model, constituted by two (sometimes more) input spaces (source and target spaces), generic space, and blended space, together forming a fundamental integration network. Generic space contains the most abstract elements (frames, schemes, and roles) that are inherent in both input spaces. Blended space encompasses the selected structural elements from each input space and, often, generates its own new emergent structure. In turn, this new derived structure can further be "integrated" with other mental spaces - both blended and input spaces, resulting in the emergence of another blended space. 
For example, the mechanism of conceptual integration involved in the motivational structure of the Ukrainian common name "pomylkovyi yedynorih" (false Unicorn) (nomenclature name Chamaelirium) relies on several sequential levels of conceptual integration:

Input source space (hereinafter - ISS) 1: Unicorn (the isomorphic ISS associated with the myth, is also revealed in the blending processes underlying the motivational structure of the English common name for the same plant - False Unicorn Root.

Input target space (hereinafter - ITS) 1: part of the plant (root).

Generic space (hereinafter - GS) 1: involves the two frames: (a) appearance - the horn-like shape of the root, which turns upward on the end, and (b) healing properties of both the root and the unicorn's horn (the latter has been credited with numerous healing properties, and was also considered a universal antidote (Shepard, 2000).

Blended space (hereinafter - BS) 1: involves metonymic shift based on partonim-holonim semantic relations (the substitution of the part of fantastic creature by its entire name Unicorn). An allomorphic characteristic of an English common name may be the absence of a metonymic transfer as, along with the name Unicorn Root, there is also a name False Unicorn Root.

ISS 2 - genuine ginseng.

ITS 2 - plant resembling ginseng.

ITS 3 = BS1 - Unicorn-named plant.

GS 2: similar appearance and healing properties.

BS 2: false Unicorn, i.e. a plant named the Unicorn that resembles ginseng but differs from it.

Conceptual integration involves three blending processes: composition, completion, and elaboration. Composition entails the attributing some relation between the elements of input spaces. The process of completion occurs when blended structure matches some background knowledge in long-term memory. Elaboration implies further development of the "scenario" in the blend with its mental or physical simulation.

In above example, the composition consists, on the one hand, of attributing to the root the quality of Unicorn based on its similar appearance and healing properties with Unicorn horn, and, on the other hand, of differentiation of the plant from the ginseng, which it resembles in appearance and properties. The completion relies on partonym-holonym metonymic shift with replacing the part of a fantastic animal by the whole creature. Elaboration involves development of the obtained BS1 with other mental spaces, based on input source space "another plant" and input target space "Unicorn associated plant", added by further metaphorical simulation (false Unicorn).

Blending presupposes the mechanism of compression, considered by J. Fauconnier and M. Turner (Fauconnier, Turner, 2000) one of the main aspects of their theory. Relationships of compression, i.e. part - whole, cause - effect, etc., are established between the input mental spaces and in the process of conceptual blending result in a new structure in the emerging integrated space. In above example, BS1 displays the compression relationship of the "part-whole" type, while BS2 conveys the cause - consequence compression (if a plant looks like but is not ginseng, that is, it is a false ginseng, then this feature is transferred into the name resulted from BS 1, associating root with unicorn: false unicorn).

\section{METHODOLOGY}

Even though some researchers (Coulson, Matlock, 2001) are increasingly inclined to believe that the theory of conceptual integration and the theory of conceptual metaphor (Lakoff, Johnson, 1980, 1999; Lakoff, Turner, 1989) organically complement each other, our article, nevertheless, uses the models proposed by G. Fauconnier and M. Turner. This choice of research perspective and methods of analysis is due to the fact that the metaphorical folk names of the plants often reveal unexpected, original examples of conceptualization that cannot be explained in terms of the theory of conceptual metaphor. In particular, the corpus of our material shows that the motivational structure of some metaphors presupposes a projection between more than two conceptual areas as shown in the example above.

Another argument in favor of using the conceptual integration method is that blending is also applicable to the construction of linguocultural symbolic meanings (Lindell, 1998, p. 283-314), often involved in the process of folk nominations for homeopathic plants. Referring to the analyzed example, it should be said that other names for the Chamaelirium luteum plant contain an archetypal-symbolic component based in two languages on both the cultural archetypes of a fairy tale (fairy wand) and mythology symbols (Devil's Bit, etc.). Symbolic features implied by the internal form of metaphorical names in English and Ukrainian languages are "protection from evil" and "connection with the spirit world". These meanings are formed by the metaphorical shift based on the ambivalent qualitative ontological characteristics of the plant - both functional and associated with its appearance.

On the one hand, it "gives vital energy", while, on the other hand, it has a scary look due to the upright wooden stems covered with harmful and irritating thorns. Blending process for metaphorical model of the plant nomination as fairy wand includes:

ISS - a fabulous item; ITS - the root;

GS - (a) healing properties of the plant similar to wonderful qualities of Fairy Wand; (b) external resemblance of the root to the Wand.

For the second nomination Devil's Bit blending involves: ISS - an attribute of a mystical being (bit (mouthpiece) itself is endowed with symbolic connotations: smoking as a way of introducing into a trance); ITS -wooden stems of 
the plant; GS - (a) supernatural healing qualities of the plant; (b) scary looks of wooden stems covered with thorns associated with the scare looks of a mystical being, (c) external resemblance of the wooden stems and a bit (mouthpiece).

\section{SAMPLING}

The corpus of metaphors to denote English and Ukrainian homeopathic plants was selected from dictionaries of Ukrainian scientific and folk names of plants (2004), Dictionary of plant names : over 100,000 names of about 10,000 species and varieties of flowering plants and fern-like plants in Latin, Russian, English and Chinese (hieroglyphic and Latin transliteration) by A.I. Schroeter et al (1999), Encyclopedic reference book of medicinal plants (1992), website of the National center for homeopathy and numerous other on-line resources.

\section{DisCUSSION AND MAJOR FINDINGS}

Among the isomorphic input source spaces, underlying the metaphorical nominations of homeopathic plants in the compared languages, the paper identified:

(1) another plant: metaphorical motivations in generic space are formed either by (a) sensory evaluations based on the similarity of taste or smell of one plant with gustatory or odorative characteristics of another plant or (b) similar healing properties of the compared plants: Water pepper and its Ukrainian calque vodianyi peretz (nomenclature name Polygonum hydropiper L.), Wood sorrel and similar name schavel lisovyi in Ukrainian (Rumex sylvestris), False jasmine and its calque pomylkovyi zhasmyn (Gelsemium sempervirens); bog rosemary and dykyi rozmaryn (wild rosemary) (Andromeda polifolia): basic generic feature - the similarity of the leaves of real rosemary and its resembling wild plant;

(2) plant distribution area: baraniacha trava, lamb grass: ISS - lamb grazing place; ITS - grass; GS - place where the plant grows; place where the lamb graze; BS - metaphorical elaboration, based on the possessive propositional scheme. The nomenclature term Arnica montana also got its name from the Greek word "Amos" which means "lamb";

(3) mythical person or creature: Jupiter's staff (Verbascum thapsus L.). In the Ukrainian language, the closest to the motivational basis of the English name, based on the plant appearance, is the folk name tsarski svichi (the royal candles), however, deprived of mythological motivation. At the same time, another common name for the same plant, "doobidnytsia" (something that precedes the worship) is directly related to the religious conceptual sphere (as "obidnytsia" is defined as a daily worship served instead of the Liturgy). However, the internal form of such a nomination is opaque;

(4) a diseased organ or symptom of a disease: Colic Root (Aletris farinose); puposhna trava (umbilical herb), shlunkova trava (gastric herb) to denote Potentilla erecta; lungwort, lehenevyi mokh (lung moss) (Sticta pulmonaria): ISS - a diseased organ or symptom of a disease; ITS - plant / part of the plant; GS - healing properties of the plant, associated with the treatment of a certain disease;

(5) holiday / season: Christmas fern and its Ukrainian equivalent rizdvianyi paporot' (Polystichum acrostichoides): ISS - Christmas tree (green in winter); ITS - fern leaves; GS - evergreen fronds of the fern associating with evergreen Christmas tree; BS - based on the (a) composition attributing to the fern the quality of evergreen Christmas tree; (b) completion that relies on partonym-holonym metonymic shift with replacing the part of plant, its leaves, with by the whole plant; (c) elaboration involving differentiation of the fern from non-evergreen plants, development of the obtained BS by means of additional ISS "winter holiday" and background information that trees are not green in winter, as well as reduction of the comparative relations (green as Christmas tree) with the replacement of the object to which the Christmas qualities are attributed;

(6) behavior: cuckoo flower and its Ukrainian equivalent zozulin tsvit (Cardamine pratensis): ISS - Cuckoo; ITS flowering; GS - bloom in the time when the cuckoo sings; BS - metaphorical nominative shift, based on the possessive propositional scheme; beggarticks, prychepa in Ukrainian (Bidens): ISS - annoying person in motivational structure of Ukrainian term, and beggar - in English common name; ITS - sticky seeds; GS - way of behaving: plant seeds that grab hold of whatever they touch and a person with similar pattern of behavior; fly honeysuckle and its Ukrainian calque zhymolost' mushacha (Lonicera xylosteum) (attracts flies); bee balm (Monarda) (attracts bees); fleabane - Erigeron annuus (drive away fleas) (ISS and generic features of the last two metaphoric folk names are not identified in the Ukrainian nominations of the same plants).

One of the most frequent models of metaphorization, characteristic of both Ukrainian and English folk names, is based on implicit comparison of the plants with body parts. The most common input source spaces, in this vein, involve parts of the body of:

(a) an animal: in Ukrainian - levova pascha (lion's mouth), in English - snapdragon to denote the same botanic name Antirrhinum Tourn; cat's paw and its Ukrainian correlate kotyacha lapka corresponding to botanic name Antennaria dioica Gaertn (Walker, 2014); zaiache vukho (hare's ear) in Ukrainian, designating Verbascum lychnitis. However, the English name white mullein, denoting the same plant, has a different motivational basis - unrelated to somatism though conveying tactile sensations of the plant associated with the softness - intersecting, in this vein, with the metaphorical pattern of the Ukrainian term hare's ear (compare with definition in Online Etymology Dictionary: 
mullein is derived from Anglo-French moleine (French moulaine), perhaps literally "the soft-leaved plant," from French mol "soft" and Latin mollis "soft").

(b) a person: lady's hair, maid's hair (the botanic name - Adiantum Pedatum L. (folk names of this plant are not identified in the Ukrainian language where the only nomination adiantum stopovydnyi is a half-calque from the Latin term); bearded iris in English, kosytsia (braid) in Ukrainian (Iris germanica): both the Ukrainian and English folk names use somatisms albeit different; the blending space of the Ukrainian nomination, based on the similarity of the plant and the braid, results in metonymy, while English folk name relies on a metaphorical shift;

(c) a bird: Ukrainian name voronyache oko (Raven eye) to denote Paris quadrifolia in Ukrainian; Pheasant's-eye (Adonis annua). The correlative names of this plant in the Ukrainian language volosatyk (hairy), mokhnatyk (shaggy) lose the motivational attribute "part of the bird" as their motivational structure is related to an anthropomorphic source space, reflecting a plant association with a shaggy person.

So, genetic characteristics uniting the input source space "the part of the body" and input target space "the part of the plant" involve the similar shape of the plant (a part of a plant) and the body part, as well as their location in the body, sometimes in combination with similar functions.

English metaphorical nominations can be either isomorphic or allomorphic to their Ukrainian intercultural synonyms in relation to the underpinning mental spaces, subdomains, and prominent features.

In particular, isomorphic in terms of the input source space, subdomain and prominent feature are the Ukrainian folk name kotyacha lapka (cat's paw) and its English correlate catsfoot and stoloniferous pussytoes:

ISS is Cat.

ITS is Plant.

GS: involves at least two similar characteristics of the compared referents: white-woolly appearance and sensation on the stems associating with the sensation of touching a cat's paw that become prominent characteristics in the blended space. So, the metaphor is based on subject-sensory imagery, related to the tactile and visual perception of the plant.

Partial isomorphism is identified in the internal forms of the Ukrainian nomination levovyi zev (lion's mouth) and its corresponding English common name snapdragon, designating the plant Antirrhinum Tourn. Both nominative models underlying the internal form of nominations imply a metonymic-metaphorical transfer of the properties of an animal (its specific part) to a part of a plant. Isomorphic input target space for levovyi zev and Snapdragon is "Plant" with a subdomain "Flower". Allomorphic input source spaces are "real animal" and "fantastic / mythological animal" with the same isomorphic subdomain "jaws". Generic characteristics juxtapose the similar appearance of the open flower and open mouth of the scary animal.

At the same time, the generic features resulted in conceptual integration in the two blending spaces are different. In contrast to the Ukrainian metaphoric common name, based on the similarity of a part of the body (mouth) with an open flower, the English metaphor is rather associated with an action, metonymically embodied in the verbal noun "snap" denoting "an abrupt closing". So, the English metaphor is finally motivated by the resemblance of an open flower with the mouth of a predator in the process of capturing

A significant part of English metaphorical common names of the homeopathic plants is allomorphic to their Ukrainian correlates in terms of all components of the metaphorical semiosis. In addition, the English metaphoric nominations are distinguished by a more diversified mental source spaces and generic features, sometimes also associated with symbolic connotations, compared to the Ukrainian nominations.

For example, the Ukrainian common name voronyache oko (Raven eye), that is the somatism-based metaphor, correlates with the English terms herb-paris or true lover's knot. While the first English name is a partial lexical borrowing from Latin (Paris quadrifolia), the second nomination is much more ambiguous and implicit in its onomasiological structure.

In particular, the input source and target spaces of the metaphor true lover's knot are, correspondingly, "knot tying features" and "herb appearance". The generic space is based on such conceptual characteristics as (a) the cross-shaped connection of four leaves resembling the shape of folding a rope before tying a knot; (b) the equality and harmony of all parts of the flower, also known as the "herb of equality" that relates to the symmetry and proportionality of the knot of the same name.

In addition, the metaphorical nominative model is also based on the archetypal symbolic component, developed due to the association of the conceptual domains of "Harmony" ("suggested" by the plant's symmetry) and "marriage". Such an association evolved from the use of the herb in marriage rituals. In this case, the metaphorization model involves an additional input space associated with such a structural component of a metaphoric expression true lover's knot as "love" with additional functionally associated components "knot = marriage bonds", underlying something possessing joining capacity. At the same time, the key concept of generic space is "harmony" (both in marriage and in the form of a flower).

Other symbolic connotations of love, friendship and affection are conveyed, in their turn, by the name of the type of knot, namely the true lover's knot (about the symbolism of this knot - see Clifford, 1944, p. 386-388).

Thus, the metaphorical model of the nomination associated with the homeopathic herb is distinguished by a plurality of input spaces and generic features that determine the result of blending. Along with the input source space ("knot tying features") and input target space ("herb appearance") of the first order, there are additional implicit input spaces of 
the second order "Marriage" and "Plant's Symmetry=Harmony", which, in turn, are complicated by the secondary linguocultural symbolic connotations "a plant under consideration is one of the symbols of marriage", "A knot visually resembling the plant was once considered a symbol of love", as displayed by Table 1:

TABLE 1.

CONCEPTUAL-MOTIVATIONAL BASIS OF THE COMMON NAME OF THE PLANT TRUE LOVER'S KNOT (PARIS QUADRIFOLIA)

\begin{tabular}{|l|l|l|}
\hline Input source space 1 & Generic space & Input target space 1 \\
\hline knot tying features & Symmetry, harmony & herbearance \\
\hline Marriage & harmony + linguocultural symbolic & herb appearance \\
love & connotations conveyed by plant's name + & herb sacred function in marriage rituals \\
devotion & symbolic connotations conveyed by the & \\
& knot's nomination & \\
\hline
\end{tabular}

At the same time, the correlative Ukrainian name "voroniache oko" (Raven eye) is much less complex in relation to its onomasiological structure, reproducing one of the most frequent metaphorical nominative models:

ISS: a body part of the animal / a bird (an eye).

ITS: the part of the plant (a berry).

GS: visual imagery, involving such conceptual characteristics as "the similar shape", "bluish-black color", "shine", location (upper body - the upper part of the plant) associating the berry appearance with the raven eye.

Further metonymic shift in the nominative model results in such Ukrainian synonymous doublets as the voronetz (little crow), voroniachi yahody (crow berries), voronnia trava (crow grass). Metonymic shift relies here on the paradigm of semantic relations between the holonym (a bird: Raven) and its body partonym (Raven eye). In the metaphoric model under consideration, the holonym replaces the partonym even though it is the partonym that determines the prominent motivating feature of the metaphoric onomasiological structure. In addition, in the second two nominations voroniachi yahody (crow berries) and voronnia trava (crow grass), the specificity of the metonymicmetaphorical nominative shift is no longer determined by the comparative, but by the possessive basic propositional scheme.

Other synonymic common names designating the same plant involve the nominative metaphoric model based on combining comparative and possessive characteristics, reinterpreted by folk linguistic mentality in symbolic plane. A common name vovchi ochi (wolf eyes) involves two possible interpretations: the first one is close to the motivational basis of the metaphor voroniache oko (Raven eye).

ISS: a body part of the animal (eyes).

ITS: the part of the plant (a berry).

GS: visual imagery constituted of the "shape", "color", and "glitter of eyes", associating the black eyes of a wolf with the berry appearance.

However, the second interpretation involves the additional symbolically reinterpreted mental spaces related to the popular beliefs about the wolf as the personification of evil, meanness, and death. In the Encyclopedic dictionary of symbols of Ukrainian culture, the wolf is defined as "a symbol of evil, greed, cruelty, hypocrisy, lies, bloodthirstiness, submissiveness, ingratitude, unworthiness, conspiracy of evil people, hungry life, hunger" (Encyclopedic dictionary of symbols, 2015, p. 137).

In this vein, the associated source and target mental spaces are related to the properties of the poisonous plants and the qualities of the wolf, attributed to it by folk psychology (in particular, a similar interpretation is found in Ukrainian sources devoted to traditional medicine source: https://medukpro.ru/narodna-medicina/6184-vovcha-jagoda.html). Metaphorical model can be presented as follows:

ISS 2: evil qualities of the wolf

ITS 2: poisonous properties of the plant

GS 2: danger to human life.

Even more complex symbolism is the basis for the nomination khrest trava (grass-cross) to designate the same plant. On the one hand, it is based on visual association of the plant with a cross (the connection of four leaves like a cross). In this case, the simple one-level model of conceptual integration involves: ISS: cross; ITS: plant leaves configuration; GS: visual similarity of symmetric leaves and a cross.

On the other hand, a secondary metaphorical-metonymic shift as well as additional symbolic meanings associated with the name of the plant relates to the function of the cross as a protection from evil forces. In this connection, the khrest trava (grass-cross) was attributed a supernatural ability to protect its owner. In ancient times, it was believed that such berries, sewn into clothing, could save a person from evil spells. During epidemics, they were worn on the body to protect against the pestilence.

However, another interpretation of the sacred properties attributed to the grass can also be connected, in our opinion, with its poisonous properties. An amulet in the old days often became a thing associated with something terrible (fangs of terrible animals, etc.), since it was believed that such an amulet not only could drive away evil but also cause the forces of evil to panic.

Motivational structure of the different Ukrainian folk names to designate Paris quadrifolia is shown in Table 2. 
TABLE 2.

CONCEPTUAL-MOTIVATIONAL BASIS OF THE UKRAINIAN FOLK NAMES TO DENOTE PARIS QUADRIFOLIA

\begin{tabular}{|c|c|c|}
\hline \multicolumn{3}{|l|}{ voroniache oko (Raven eye) } \\
\hline Input source space & Generic space & Input target space \\
\hline a body part of the animal a bird (an eye). & $\begin{array}{l}\text { the similar shape, bluish-black color, shine, } \\
\text { location (upper body - the upper part of the } \\
\text { plant) }\end{array}$ & the part of the plant (a berry) \\
\hline \multicolumn{3}{|l|}{ vovchi ochi (wolf eyes) } \\
\hline ISS 1: a body part of the animal (eyes) & shape, color, glitter of eyes & ITS 1: the part of the plant (a berry) \\
\hline ISS 2: evil qualities of the wolf & danger to human life. & ITS 2: poisonous properties of the plant \\
\hline \multicolumn{3}{|l|}{ khrest trava (grass-cross) } \\
\hline Cross & $\begin{array}{l}\text { visual similarity of symmetric leaves and a } \\
\text { cross; } \\
\text { symbolic meaning: protection from evil }\end{array}$ & plant leaves \\
\hline
\end{tabular}

Allomorphic in terms of onomasilogical structure is the English metaphorical common name larkspur and its Ukrainian correlate zhyvokist (literally translated - a truncated version of "alive bone") to denote the same botanic name Delphínium.

For the English metaphoric nomination, the input source space involves the somatism - a body part of the bird; the target space is the part of the plant - the flower; the generic space is based on the visual resemblance of the elongated petals on each bloom of the flower with the hind claws of a lark.

Motivational basis of the Ukrainian metaphor involves:

ISS: musculoskeletal system.

ITS: healing properties of the plant.

GS: recovery, revitalization of musculoskeletal system due to healing properties of the plant.

Motivational structure of the Ukrainian and English folk to designate Delphínium is shown in Table 3.

TABLE 3.

CONCEPTUAL-MOTIVATIONAL BASIS OF THE UKRAINIAN AND ENGLISH FOLK NAMES TO DENOTE DELPHÍNIUM

\begin{tabular}{|c|c|c|}
\hline \multicolumn{3}{|l|}{ zhyvokist ("alive bone") } \\
\hline Input source space & Generic space & Input target space \\
\hline $\begin{array}{l}\text { Healthy } \\
\text { musculoskeletal system }\end{array}$ & recovery, revitalization & healing properties of the plant. \\
\hline \multicolumn{3}{|l|}{ Larkspur } \\
\hline a body part of the bird & $\begin{array}{l}\text { elongated petals on each bloom of the flower } \\
\text { associating with the hind claws of a lark. }\end{array}$ & a part of the plant (its flower) \\
\hline
\end{tabular}

Analysis of the internal form of the Ukrainian metaphoric nomination kanadska vovcha stopa (Canadian wolf's foot) to denote Sanguinaria canadensis reveals a conceptual model constituted by the target input space "the part of the plant" and source input space "the part of the animal's body". The conceptual feature projected into the generic space is the external similarity of the shape of the plant to that part of the animal's body, marked by somatism "foot".

However, the conceptual blending reflected in the internal form of the English metaphorical composite bloodroot, which denotes the same plant, is the result of the interaction of two source and two target spaces:

ISS 1: "blood"

ITS 1: "liquid"

GS 1: common feature - red colour

ISS 2: part of a living organism

ITS 2: Part of a plant (root)

GS 2: the property of root and a living organism to emit blood-like red liquid when damaged.

As a result of the projection of two conceptual features (blood-like red fluid is released due to damage) in the generic space, a new meaning emerges in the blended space: the root bleeds as a damaged part of a living organism, which determines the metaphorical-metonymic nomination.

Thus, the Ukrainian composite and its conceptual equivalent in English has three isomorphic conceptual features: (a) belonging to a living being, (b) metonymic semantic relations (part of the body - part of the plant), which is the basis of the metonymic component of the nomination, as well as (c) the implied seme "comparability" (look like) - the basis of the metaphorical nomination.

However, allomorphic are the input source spaces and the features of the generic space that determine the conceptual blending and differences in the motivational basis of Ukrainian and English metaphors designating the same plantreferent as displayed by Table 4. 
TABLE 4.

CONCEPTUAL-MOTIVATIONAL BASIS OF THE UKRAINIAN AND ENGLISH FOLK NAMES TO DENOTE SANGUINARIA CANADENSIS

\begin{tabular}{|c|c|c|}
\hline \multicolumn{3}{|c|}{ kanadska vovcha stopa (Canadian wolf's foot) } \\
\hline Input source space & Generic space & Input target space \\
\hline the part of the animal's body & $\begin{array}{l}\text { similarity of the shape of the plant and part } \\
\text { of the animal's body }\end{array}$ & the part of the plant \\
\hline \multicolumn{3}{|c|}{ Bloodroot } \\
\hline ISS 1: blood & GS 1: red colour & ITS 1: liquid \\
\hline ISS 2: part of a living organism & $\begin{array}{l}\text { GS } 2: \text { the property of root and a living } \\
\text { organism to emit blood-like red liquid when } \\
\text { damaged. }\end{array}$ & ITS 2: part of a plant (root) \\
\hline
\end{tabular}

\section{CONCLUSIONS}

The paper identifies similar and different features in metaphorical folk names of English and Ukrainian homeopathic plants from viewpoint of their cognitive and linguocultural underpinning. Based on the method of conceptual integration with some elements of symbolic analysis, the article reached the following main findings.

Isomorphism of metaphorically-based plant nominations in the compared languages relies on their similar input source spaces of motivation, i.e. plant distribution area; mythical person or creature; a diseased organ or symptom associating healing properties of the plant with the organ treated by it or the mode of its treatment; holiday; "behavior" with generic features associating plant properties with human behavior; "body parts of the animal, bird or human", suggesting these parts similarity with the plant part in shape, location and functions; "another plant" - with common gustatory or odorative features of the associated plants or their similar healing properties.

Isomorphic for both languages are the compound blending models that presuppose more than two input spaces and the involvement of the obtained blend space in new blending, including those complicated by the linguocultural symbolic connotations. Isomorphism is also revealed in metonymic compression in blended spaces, based on holonympartonym shifts, possessive and comparative schemas.

Allomorphic input sources of English metaphors involve the spheres of "artifact", "body fluids", "mythological characters", "fantastic creature", "particular patterns of behavior" and their corresponding characteristics associated with the plant - in contrast to the Ukrainian intercultural synonyms where such conceptual input spaces have not been identified.

\section{REFERENCES}

[1] Baker, Margaret. (2011). Discovering the Folklore of Plants, 3rd edition. Oxford: Shire Classics.

[2] Čižmárová, M. (2017). Nominačné modely v botanickom názvosloví. 2. dopl. vyd. Prešov: Prešovská univerzita v Prešove, Filozofická fakulta.

[3] Clifford, A. W. (1944). The Ashley Book of Knots. New York: Doubleday.

[4] Coulson, S., Matlock, T. (2005). Metaphor and the space structuring model. Metaphor \& symbol, Vol. 16, N 13 L.; N.Y., 295316.

[5] Dietz, S. Theresa. (2020). The Complete Language of Flowers: A Definitive and Illustrated History. New York: Wellfleet Press.

[6] V.P. Kotsura, O.I. Potapenko, V.V. Kuybids. Ed. (2015). Encyclopedic dictionary of symbols of culture of Ukraine - 5th type. Korsun-Shevchenkivsky: FOP Gavryshenko V.M. [in Ukrainian]

[7] Fauconnier, G., Turner, M. (1996). Blending as a central process of grammar. Conceptual structure, discourse, and language. Ed. Goldberg A. Stanford: CSLI.

[8] Fauconnier, G., Turner, M. (1998). Conceptual Integration Networks. Cognitive Science. Vol. 22(2), 133-187.

[9] Fauconnier, G., Turner, M. (2000). Compression and global insight. Cognitive linguistics. 11, N 3/4. 283-304.

[10] Fauconnier, G., Turner, M. (2002). The Way We Think: Conceptual Blending and the Mind's Hidden Complexities. New York: Basic Books.

[11] Grodzinsky, A.M. (1992). Medicinal plants: Encyclopedic reference book. Kyiv: Ukrainian Encyclopedia Publishing House. M.P. Bazhana. [in Ukrainian]

[12] Kay, Q.O.N. \& Stevens, D. (1986). The frequency, distribution and reproductive biology of dioecious species in the native flora of Britain and Ireland. Botanical Journal of the Linnean Society. Vol. 92, N 1, 39-64.

[13] Kobiv, Yu. (2004). Dictionary of Ukrainian scientific and folk names of vascular plants. Kyiv: Scientific Opinion. [in Ukrainian]

[14] Lakoff, G., Johnson, M. (1980). Metaphors we live by. Chicago: Univ. of Chicago press.

[15] Lakoff, G., Johnson, M. (1999). Philosophy in the flesh: The embodied mind and its challenge to Western thought. Chicago: Univ. of Chicago press.

[16] Lakoff G., Turner, M. (1989). More than cool reason: A field guide to poetic metaphor. Chicago: Univ. of Chicago press.

[17] Lindell, S. (1998). Grounded blends, gestures, and conceptual shifts. Cognitive linguistics. Vol. 9, N 3., $283-314$.

[18] Mullein | Origin and meaning of mullein by Online Etymology Dictionary. Retrieved Sept 21 from etymonline.com.

[19] National Center for Homeopathy. Retrieved Sept 10 from homeopathycenter.org.

[20] Schroeter, A.I. .et al (1999). Dictionary of plant names: over 100,000 names of about 10,000 species and varieties of flowering plants and fern-like plants in Latin, Russian, English and Chinese (hieroglyphic and Latin transliteration). Koenigstein, Germany: Koeltz Scientific Books.

[21] Shepard, Odell. (2000). The Lore of the Unicorn. London: Unwin and Allen. 
[22] Turner, M., Fauconnier, G. (2000). Metaphor, Metonymy, and Binding. Metaphor and Metonymy at the Crossroads: A Cognitive Perspective, ed. A. Barcelona. Berlin; New York: Mouton de Gruyter, 133-145.

[23] Walker, K.J. (2014). Antennaria dioica (L.) Gaertn. Mountain Everlasting. Species Account. Botanical Society of Britain and Ireland.

Nataliia Kravchenko graduated from Taras Shevchenko National University of Kyiv, Ukraine, in 1985. Obtained PhD in 1990 and DrSc Degree in General Linguistics in Taras Shevchenko University of Kyiv, Ukraine in 2007.

She is a professor at Kyiv National Linguistic University, Ukraine. The author of 5 monographs, 2 textbooks, more than 150 articles. The current research interests include: cognitive studies, discourse-analysis, pragmatics, stylistics, cultural studies, etc.

Ms. Kravchenko is a scientific supervisor of $\mathrm{PhD}$ and Doctorate students.

Nataliia Yemets graduated from Kyiv National Linguistic University in 2003. Obtained PhD in Germanic Languages in KNLU, Kyiv, Ukraine in 2021.

She works on the position of a senior lecturer in KNLU, Kyiv, Ukraine. The author of more than 12 articles. The current research interests include: contrastive lexicology and stylistics, cognitive studies, conceptology, poetics.

Ms. Yemets is a member of The Center for Ukrainian-European Scientific Cooperation.

Olha Kurbal-Hranovska graduated from Taras Shevchenko National University of Kyiv in 2014 (Master of Translation-diploma with honours), Nizhyn Mykola Gogol State University in 2018 (Master of Psychology). A postgraduate student of Philology in Kyiv National Linguistic University, Kyiv, Ukraine.

She works on the position of a lecturer in KNLU, Kyiv, Ukraine. The current research interests include: translation studies, contrastive lexicology, semantics, literary theory.

Ms. Kurbal-Hranovska is a member of KNLU post-graduate students scientific society. 